OPEN ACCESS

Edited by:

Thomas Hartung,

University of Konstanz, Germany

Reviewed by:

Paul Jennings,

Innsbruck Medical University, Austria

Michael Balls,

Retired from the European Centre for the Validation of Alternative Methods, Joint Research Centre, Italy

*Correspondence:

George D. Loizou george.loizou@hsl.gsi.gov.uk

Specialty section:

This article was submitted to

Predictive Toxicology,

a section of the journal

Frontiers in Pharmacology

Received: 20 May 2016

Accepted: 06 July 2016

Published: 21 July 2016

Citation:

Loizou GD (2016) Animal-Free

Chemical Safety Assessment.

Front. Pharmacol. 7:218

doi: 10.3389/fphar.2016.00218

\section{Animal-Free Chemical Safety Assessment}

\author{
George D. Loizou* \\ Health Risks, Health and Safety Laboratory, Health and Safety Executive, Buxton, UK
}

The exponential growth of the Internet of Things and the global popularity and remarkable decline in cost of the mobile phone is driving the digital transformation of medical practice. The rapidly maturing digital, non-medical world of mobile (wireless) devices, cloud computing and social networking is coalescing with the emerging digital medical world of omics data, biosensors and advanced imaging which offers the increasingly realistic prospect of personalized medicine. Described as a potential "seismic" shift from the current "healthcare" model to a "wellness" paradigm that is predictive, preventative, personalized and participatory, this change is based on the development of increasingly sophisticated biosensors which can track and measure key biochemical variables in people. Additional key drivers in this shift are metabolomic and proteomic signatures, which are increasingly being reported as presymptomatic, diagnostic and prognostic of toxicity and disease. These advancements also have profound implications for toxicological evaluation and safety assessment of pharmaceuticals and environmental chemicals. An approach based primarily on human in vivo and high-throughput in vitro human cell-line data is a distinct possibility. This would transform current chemical safety assessment practice which operates in a human "data poor" to a human "data rich" environment. This could also lead to a seismic shift from the current animal-based to an animal-free chemical safety assessment paradigm.

Keywords: animal-free, safety, assessment, metabolomics, personalized, medicine, biosensors

\section{INTRODUCTION}

In a paper titled "The feasibility of replacing animal testing for assessing consumer safety: a suggested future direction" Fentem et al. (2004) discussed how the new "omics" technologies; genomics, transcriptomics, proteomics and metabonomics could be used in the future to replace animal-based data in human chemical safety assessment. At that time, a major impediment to progress was that much of these data were generated in a clinical setting and not in abundance in the public domain. They recommended that making these data and information generally accessible in an ethical and legal way, could lead to the translation of experimental non-animal data that could be used in safety assessment (Fentem et al., 2004).

Much has changed in the research landscape since then. The expansions of the internet, allowing greater connectivity of devices and sensors, computational speed, cloud computing and multi-disciplinary collaborations, are the main developments that characterize these changes. For example, in recent years the speed of supercomputers has increased by several orders of magnitude, boasting processing speeds of $10^{15}$ floating-point operations per second which will soon reach $10^{18}$ floating-point operations per second (Witze, 2014). Without such computational power the production of approximately 1.8 zettabytes $\left(10^{21}\right)$ of genomic, epigenomic, 
transcriptomic, proteomic and metabolomic data generated each year, roughly doubling the world's information resource every two years, would not be possible (Dearry, 2013). Indeed, more than 50,000 omics papers are published each year (Cote et al., 2014). Movements such as, Open Access in publishing (Bains, 2009), Open Source Initiative in software development ${ }^{1}$, Open Source engineered human tissue models (De Wever et al., 2015), the Open Phacts Foundation (Williams et al., 2012) and the need for multi-disciplinary approaches to the access, integration and analysis of big data sets (Schumacher et al., 2014; Alyass et al., 2015) has led to a burgeoning of collaborative research ${ }^{2}$. This in turn has led to the proliferation of publicly available databases that include omics data for human disease, as well as survey and clinical assay data on human exposure and health outcomes (Zhu et al., 2008; Sakurai et al., 2011; Kim et al., 2012; Kotera et al., 2012; Kamburov et al., 2013; Wachter and Beissbarth, 2015). This new environment is leading to significant paradigm shifts in medicine and toxicology. Indeed, medicine is being transformed into a data science (Topol, 2010; Hood et al., 2015; Topol et al., 2015).

These changes could lead to the transformation of human chemical safety assessment from a "human data poor" to a "human data rich" arena with the consequent elimination of animal-based toxicology studies that currently underpin chemical safety assessment. In this review the components that could bring about an animal-free chemical safety assessment paradigm are discussed.

\section{SYSTEMS BIOLOGY}

Contemporary methods for the diagnosis of human disease originated in the late $19^{\text {th }}$ century, and are based on simple observational correlations between clinical syndromes and pathological analysis (Loscalzo et al., 2007; Loscalzo and Barabasi, 2011). Over the same period, research followed the reductionist approach that attempts to explain complex phenomena by defining the functional properties of the individual components that make up a system (Sobradillo et al., 2011). Consequently, the research focus progressed from the whole organism (anatomy) to the organs (physiology), cells (cell biology) and ultimately to subcellular molecular interactions (genes, proteins, lipids and metabolites; molecular biology) (Figure 1). This reductionist strategy is based on the assumption that many of the functions of the whole organism can be understood by knowing the properties of the component parts (Sobradillo et al., 2011). Both the approach to the diagnosis of disease and the reductionist strategy to research have made major contributions to our understanding of health and disease, however, they have inherent significant limitations. Current methods for diagnosing disease lack sensitivity for identifying preclinical disease (i.e., identifying precursor events that support early detection and treatment), and specificity in unequivocally defining disease (Loscalzo

${ }^{1}$ http://opensource.org/history (Accessed on 20 May 2016)

${ }^{2}$ http://www.scienceeurope.org/uploads/PublicDocumentsAndSpeeches/SCs

PublicDocs/Workshop_Report_MED_Big_Data_web.pdf (Accessed on 20 May 2016) et al., 2007). The reductionist approach does not account for phenomena that emerge from the interactions of parts, and that appear as 'coordinated' functions of the individual components at higher levels of system organization (Sobradillo et al., 2011).

An alternative to the reductionist mind-set is the 'systems biology' perspective that integrates events at various levels of 'system' organization, and accounts for interactions of individual components and emerging properties that cannot be deduced from information on the single elements alone (Sobradillo et al., 2011).

Systems biology and systems medicine are characterized by the application of computational and mathematical modeling techniques that aim to unravel and understand the complexity of normal and diseased biological systems (Galas and Hood, 2009; Loscalzo and Barabasi, 2011; Chen and Snyder, 2012; Jack et al., 2013). They are biology-based, inter-disciplinary studies that deploy engineering approaches to discover emergent properties of cells, tissues and organs functioning as a system from the interactions between genetic, metabolic and cell signaling responses (Galas and Hood, 2009; Loscalzo and Barabasi, 2011; Chen and Snyder, 2012; Jack et al., 2013).

In systems biology, the implications of altered molecular and cellular components that result from exposure to chemical and non-chemical stressors, are studied and integrated across multiple levels of biological organization. That is, from genes to gene expression products, to alterations in biochemical pathways and networks and the propagation of effects from cells to tissues to organs and the whole body (Andersen et al., 2005; Zhang et al., 2010). Disease arises as a consequence of disease-perturbed networks in the diseased organ that propagate from one or a few disease-perturbed networks to many as the disease progresses. These initial disease perturbations may be due to genetic changes (e.g., mutations) and/or from exposure to stressors in the environment (e.g., infectious organisms, or chemicals). These perturbations alter the information expressed in these networks dynamically - and these altered dynamics of information flow explain the pathophysiology of the disease and suggest new approaches to diagnosis and therapy (Hood et al., 2012). By treating disease as a consequence of genetic and/or environmental perturbations of biological networks the systems approach also considers social and environmental influences that may impact health. The cross-talk of all networks is integrated in order to understand their functioning in the context of the individual (Hood and Friend, 2011; Hood et al., 2012, 2013, 2015; Smarr, 2012). Importantly, there is a growing body of evidence that these perturbations conform to biological patterns or 'signatures' that are associated with specific diseases (Nicholson and Holmes, 2006; Holmes and Nicholson, 2007; Holmes et al., 2008; Nicholson et al., 2008; Bouhifd et al., 2013).

\section{THE INTERNET OF THINGS, THE MOBILE PHONE AND PERSONALIZED MEDICINE}

"Medicine is undergoing a revolution that will transform the practice of healthcare in virtually every way" (Hood 


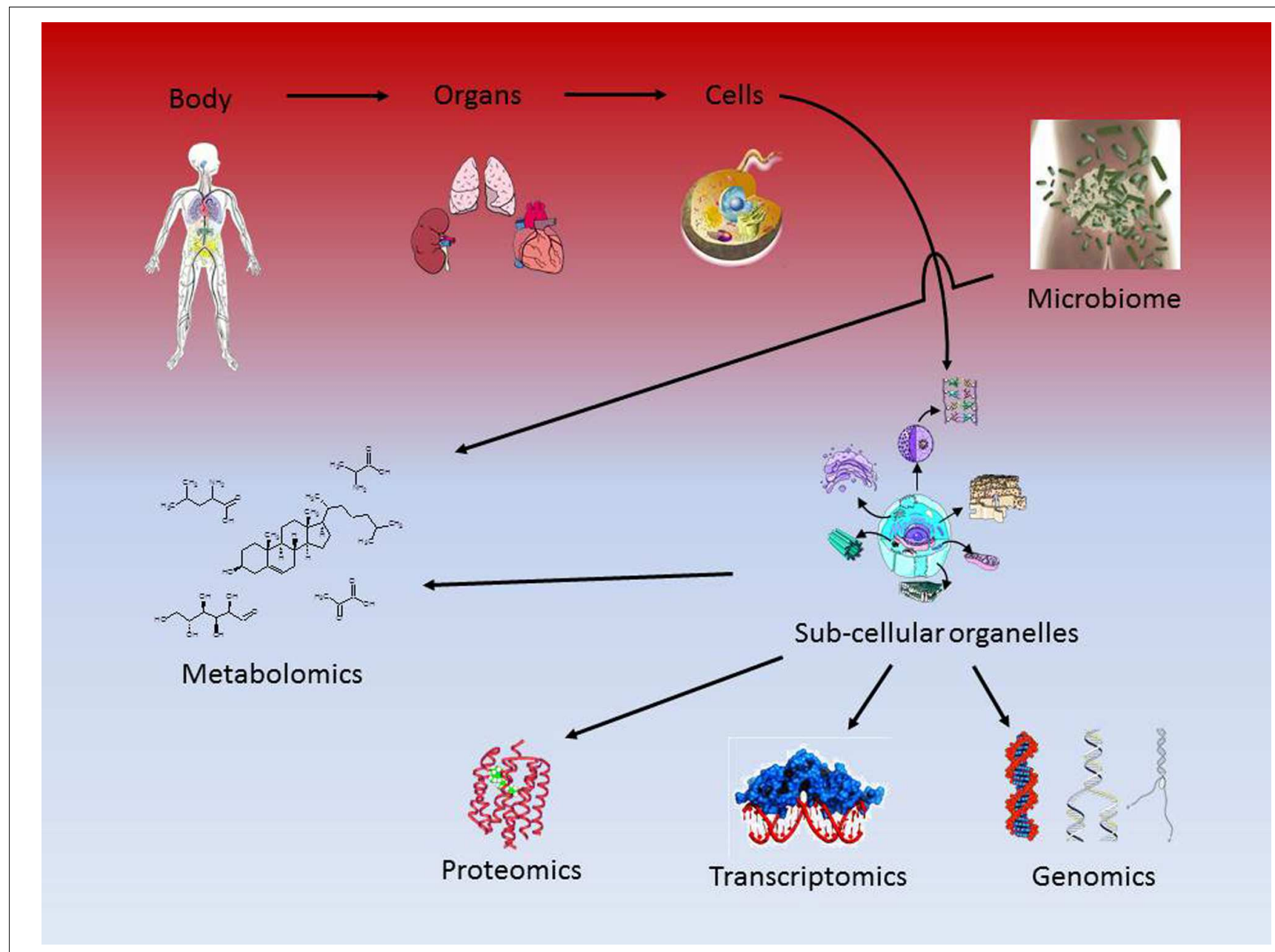

FIGURE 1 | The reductionist approach to the study of biology.

et al., 2013). The systems approach to disease is beginning to change healthcare by deploying technologies that permit the rapid sequencing of an individual human genome and the quantification of "units of biological information" such as single genes, single molecules, single cells and single organs to provide disease relevant information on health or disease for the individual. This is resulting in an explosion of patient data that is transforming "traditional biology and medicine" into an information science (Hood and Friend, 2011; Hood et al., 2012, 2013, 2015; Smarr, 2012). By harnessing the capabilities of computational analysis of "big data" the digital revolution is transforming healthcare just as it has already transformed communications, finance, retail and information technology (Hood and Friend, 2011; Hood et al., 2012, 2013, 2015). The digital revolution is making the management and analysis of extremely large biological and environmental datasets tractable and it is driving the invention of personal monitoring devices that can digitize biological information, thus enabling, the individual assessment of wellness and disease commonly described as personalized medicine (Hood and Friend, 2011; Hood et al., 2012, 2013, 2015; Smarr, 2012).
Personalized Medicine, Stratified Medicine, Precision Medicine $^{3,4}$ and P4 Medicine are interchangeable terms for systems medicine approaches to individualized healthcare (Topol, 2010; Hood et al., 2012, 2013; Smarr, 2012; Collins and Varmus, 2015; Topol et al., 2015). Personalized Medicine is a medical model that separates patients into different groups with medical decisions, practices, interventions and products being tailored to the individual patient based on their predicted response or risk of disease. It is emerging from the convergence of systems medicine, the healthcare-focussed derivative of systems biology and the digital revolution (Hood et al., 2013). It's proponents ascribe this revolution to the digital transformation of medical practice as being due to the "coalescence of the rapidly maturing digital, non-medical world of mobile (wireless) devices, cloud computing and social networking with the emerging digital medical world of genomics, biosensors and advancing imaging" (Topol, 2012). Described as the "greatest

\footnotetext{
${ }^{3} \mathrm{http}: / /$ www.acmedsci.ac.uk/more/events/stratified-personalised-or-p4-medicine -a-new-direction/ (Accessed on 20 May 2016)

${ }^{4}$ https://www.nih.gov/precision-medicine-initiative-cohort-program (Accessed
} on 20 May 2016) 
convergence in our history," this revolution has become possible because of the exponential growth of the Internet of Things (IoT) and the global popularity and remarkable decline in cost of the mobile phone ${ }^{5}$ (Topol, 2010, 2012; Mak, 2015).

The IoT has been defined as a "global infrastructure for the information society, enabling advanced services by interconnecting (physical and virtual) things based on existing and evolving interoperable information and communication technologies" ${ }^{\prime \prime}$. Fundamentally, the IoT comprises sensors, which are increasingly being embedded into smartphones and wearable devices interconnected via the internet. The ability to pack 19 million transistors into integrated circuits that occupy a $16 \mathrm{~nm}$ space explains how there are more than 2 billion transistors in some current smartphones (Topol et al., 2015). Current devices are already able to "digitize the biology of a human being" with the use of wearable sensors to quantify physiological metrics such as vital signs or relevant features of an individual's environment, provide high definition images of the anatomy, and elucidate an individual's biology by sequencing their DNA, RNA, microbiome and epigenome (Topol, 2014). In the next 5 years, individuals with hypertension and diabetes could have their blood pressure and glucose levels continuously monitored, most routine laboratory tests may be obtainable with smartphone kits and time series measurements of key biochemical variables should be feasible (Smarr, 2012; Topol et al., 2015). Billions of data points from each individual will be uploaded to a virtual cloud where sophisticated algorithms will decipher 'signal' from noise generated by the complexities of health and disease ( $\mathrm{Hood}$ and Friend, 2011; Hood et al., 2012, 2013, 2015; Smarr, 2012). Unsurprisingly, this would constitute a seismic shift from the current "healthcare" model to a "wellness" paradigm that is predictive, preventative, personalized and participatory ( $\mathrm{Hood}$ and Friend, 2011; Hood et al., 2012, 2013, 2015; Smarr, 2012).

Central to personalized medicine is biomarker tracking, specifically, the monitoring of time series measurements of key biochemical variables in an individual. Soon it may be possible to use integrated microfluidic chip technology to rapidly measure a panel of plasma proteins from a finger prick volume of whole blood. This could provide inexpensive, point-of-care, informative clinical diagnosis (Fan et al., 2008; Hood and Friend, 2011; Smarr, 2012; Hood et al., 2013, 2015). This technology could lead to the identification of organ-specific blood protein "fingerprints" that distinguish normal functioning from disease-perturbed biological networks (Hood et al., 2012, 2013). Such fingerprints or "signatures" are not confined to proteins. In fact, the field of metabolomics has tremendous potential for the identification of pre-symptomatic, diagnostic and prognostic metabolic signatures of disease, toxicity and exposure to environmental pollutants (Nicholson and Holmes, 2006; Holmes and Nicholson, 2007; Holmes et al., 2008; Nicholson et al., 2008; Bouhifd et al., 2013).

\footnotetext{
${ }^{5}$ http://www.economist.com/news/business/21600134-smartphones-reach-mass es-host-vendors-are- eager-serve-them-rise-cheap (Accessed on 20 May 2016) ${ }^{6} \mathrm{http}: / / \mathrm{www} . i t u . i n t / \mathrm{ITU}-\mathrm{T} / \mathrm{recommendations/rec}$.aspx? $\mathrm{rec}=\mathrm{y} .2060$ (Accessed on 20 May 2016)
}

The wellness paradigm may be characterized by the longitudinal monitoring of integrative personal omics profiles (iPOP) which combine genomics, transcriptomics, proteomics, metabolomics and autoantibody profiles (Stanberry et al., 2013). In this approach, changes in metabolite expression levels reflect differential expression of biological pathways and are associated with disease (Stanberry et al., 2013; Guo et al., 2015).

\section{METABOLOMICS}

Genetics alone cannot fully explain differences in disease predisposition, (Nicholson, 2006). Only about $5-10 \%$ of total human genetic variance occurs across populations and ethnic groups, although disease distributions and drug toxicity may vary greatly. Broadly speaking, genomics does not account for differences in phenotype (Holmes et al., 2008). Although a gene may be expressed and a protein may be synthesized, this protein may not be in the proper form to induce a metabolic change and therefore induce a phenotypic effect. The epigenome, which consists of non-sequence-based modifications, such as DNA methylation, is heritable and may affect normal phenotypes and predisposition to disease (Feinberg, 2010; Feinberg et al., 2010). Indeed, epigenetic changes have been shown to have a strong relationship with cancer and other common diseases (Feinberg et al., 2010).

Critical illness is characteristically the loss of metabolic homeostasis (Serkova et al., 2011; Mastrangelo et al., 2014). Monitoring the fluctuations of endogenous, low-molecular weight molecules in blood (plasma and serum) and urine is an important way to detect various human pathologies such as, cancer, cardiovascular disease, diabetes and drug and chemical toxicity (Serkova et al., 2011). Thus, metabolomics, or metabolic profiling, is the study of the quantitative description of all lowmolecular-weight $(<1 \mathrm{kDa})$ components in a biological sample. These may consist of metabolites solely under endogenous control and may also involve those originating from exogenous sources (microbiome, diet, drugs, and environmental pollutants).

The combination of genes and environment contribute to the effects observed in the metabolome as do factors such as gender, age, diet, exposure to xenobiotics and products of the gut microbiota (Mastrangelo et al., 2014). In addition, metabolomics involves the quantification of metabolites to track the developing response to a stimulus, has the advantage of being high-throughput and currently provides the best approach to delineating and understanding a biological mechanism preceding an effect (Kosmides et al., 2013; Mastrangelo et al., 2014).

The advantage of metabolomics is that it allows the evaluation of changes at a higher level of organization, that is, closer to the phenotype which therefore, should provide a more reliable indication on the state of health of the individual (Figure 2). This is possible because endogenous small molecules are at the top of the systems biology continuum and reflect and magnify (several thousands of times) perturbations that occur at the genomic, transcriptomic and proteomic level (Raamsdonk et al., 2001; Wishart, 2012). Indeed, metabolomics data are needed to construct powerful top-down systems biology tools that link 


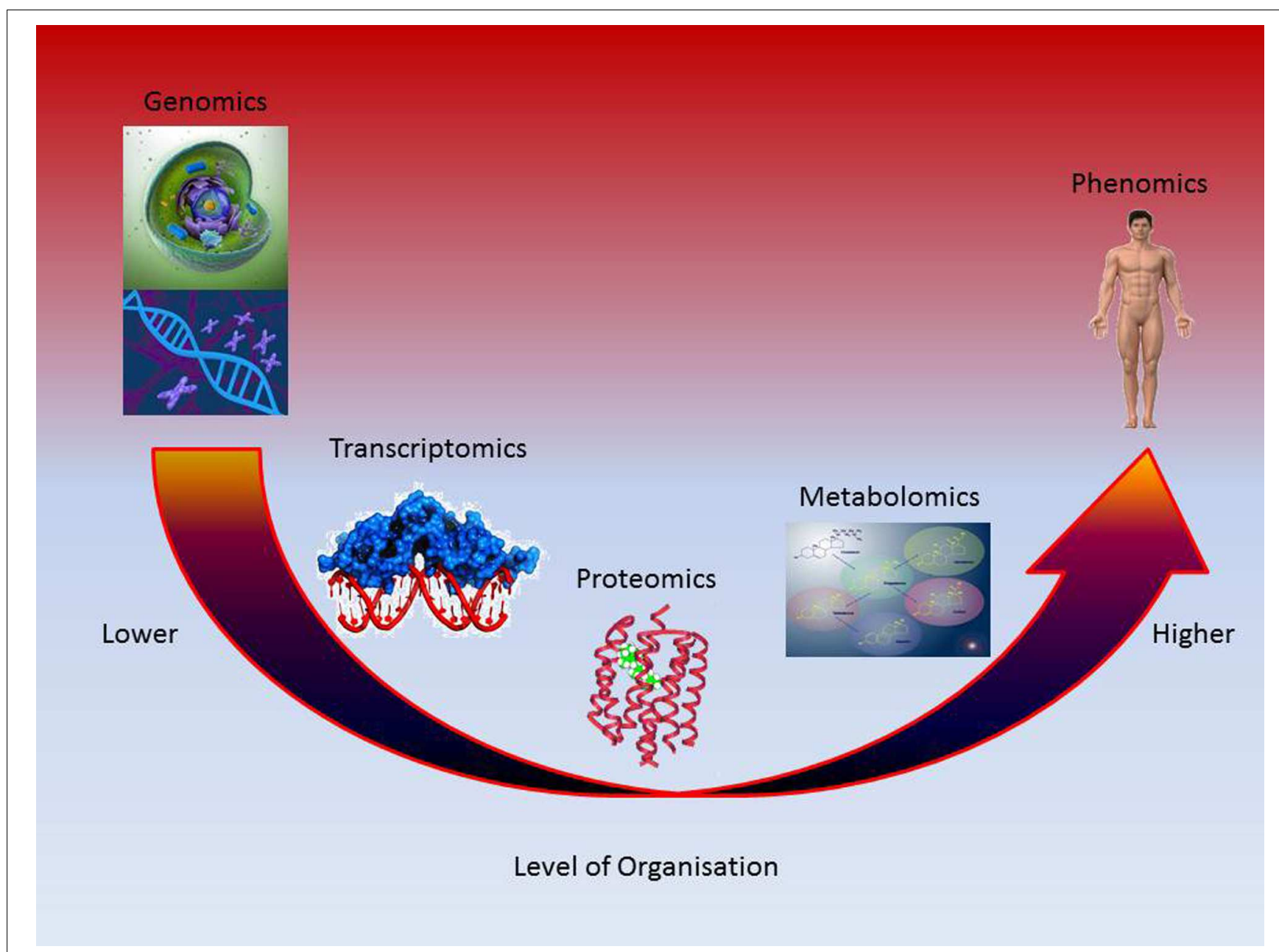

FIGURE 2 | Metabolic profiling reflects the collective effects of lower levels of organization.

the omics disciplines (Coen et al., 2008). In this respect, the ability to link the information provided by the different omics data and build a pathway of toxicity (PoT) linking an external stressor induced perturbation to a disease endpoint is analogous to the development of chemically agnostic adverse outcome pathways (AOPs) proposed for use in chemical safety assessment (Ankley et al., 2010; Bouhifd et al., 2013; Burden et al., 2015; Athersuch, 2016; Edwards et al., 2016). It could provide novel information on phenotypic characteristics and therefore the potential to investigate the output of complex, interconnected networks (Kosmides et al., 2013).

Metabolomics is very sensitive, currently capable of detecting femtomolar to attomolar $\left(10^{-15}\right.$ to $\left.10^{-18}\right)$ changes in metabolite concentrations (Veenstra, 2012). Small dietary changes, increased physical activity, elevated stress or even variations in seasons can significantly alter metabolic profiles (Monte et al., 2014). Another advantage of metabolomics is that experimental and analytical variation in commonly used methods of metabolite measurement are several orders of magnitudes smaller than biological variation which confers robustness to metabolomic signatures (Keun et al., 2002; Maher et al., 2007).

\section{TARGETED AND NON-TARGETED METABOLOMICS}

There are two main strategies used in metabolomic studies: targeted or untargeted (Fiehn, 2001; Mastrangelo et al., 2014; Guo et al., 2015). Targeted approaches are generally used in the identification of potential direct or surrogate biomarkers of health, disease and mechanistic pathways and non-targeted approaches for the detection of broad classes of biochemical to provide a comprehensive functional phenotype integrating clinical phenotypes with genetic and non-genetic factors (Jones et al., 2012; Guo et al., 2015). Non-targeted studies require the application of bioinformatics and computational tools to analyze and interpret large and complex data (Jones et al., 2012).

There are three specific applications of metabolomics, non-targeted metabolic fingerprinting and metabolic profiling and targeted metabolic profiling (Kraly et al., 2009). Nontargeted metabolic fingerprinting seeks to measure a global profile of metabolites with identification of specific profiles based on pattern recognition. A major weakness of metabolic 
fingerprinting is the inability to identify specific biomarkers for a disease state or therapeutic endpoint. Metabolic profiling is the measurement of the full complement of low-molecularweight metabolites and their intermediates, such as amino acids, carbohydrates and lipids, that reflects the dynamic response to genetic modification and physiological, pathophysiological and/or developmental stimuli (Clarke and Haselden, 2008). In targeted metabolic profiling one or two analytes are tracked with time and because of this is often excluded from the discussion of metabolomics. However, it is a very useful tool for understanding biological systems (Kraly et al., 2009).

\section{METABOLOMICS AND THE MICROBIOME}

Metabolic profiling can also include the contribution from gut microorganisms, the microbiome. The microbiome comprises more than 100 trillion microorganisms belonging to 300-500 different species that live inside and on every human being (Guarner and Malagelada, 2003). The number of microorganisms in a healthy human adult are estimated to outnumber human cells by a ratio of ten to one $\mathrm{f}^{7}$ and make up $1-3 \%$ of body mass ${ }^{8}$ (0.75-2.25 kg in a $75 \mathrm{~kg}$ person) and represents a confounding factor when interpreting genomic, proteomic or metabolomic response data (Nicholson et al., 2004; Nicholson, 2006; Kinross et al., 2008; Nicholson and Lindon, 2008). An Individual's microbiome is unique and may share as little as $1 \%$ of the same type of bacteria with other people (Kinross et al., 2008) and may change with age, diet, drugs, disease and medical or surgical intervention (Kinross et al., 2008). The gut microbiome interacts with the other systems in the body and has metabolic, trophic and protective functions (Guarner and Malagelada, 2003; Kinross et al., 2009). It influences the levels of cytochrome P450 enzymes (Nicholson et al., 2004), has a significant role in obesity (Turnbaugh et al., 2006; Kinross et al., 2008; Li et al., 2008; Calvani et al., 2010) sepsis (MacFie et al., 1999; Shimizu et al., 2006), inflammatory bowel disease, irritable bowel syndrome and colon cancer (Guarner and Malagelada, 2003). The gut microbiome contributes to interindividual variability in drug toxicities and may contribute to the bioactivation of carcinogens that would not have been metabolized by the human cells (Nicholson et al., 2005). Metabolites arising from the gut microbiome merge with endogenous chemicals thereby altering the metabolome without having influenced gene and protein expression.

\section{METABOLITE SIGNATURES}

In toxicology, extensive efforts are underway to identify signatures of toxicity which are patterns of metabolite changes predictive of the manifestation of toxicity and disease.

${ }^{7}$ https://www.bcm.edu/departments/molecular-virology-and-microbiology/rese arch/the-human-microbiome-project (Accessed on 20 May 2016)

${ }^{8} \mathrm{http} / / /$ www.nih.gov/news-events/news-releases/nih-human-microbiome-proje ct-defines-normal-bacterial-makeup-body (Accessed on 20 May 2016)
These patterns are more commonly known as metabolite signatures (Bouhifd et al., 2013, 2014, 2015). Similarly, in clinical applications the prediction of xenobiotic toxicity or drug effects in an individual based on a mathematical model of pre-intervention metabolite signatures is known as pharmacometabolomics (Clayton et al., 2006). The identification of signatures associated with toxicity, drug effects and disease endpoints in a range of media, including; serum, plasma, urine, mucosa, exhaled breath, saliva, hair, tissue and cultured cells shows steady growth and could provide human data that may be used in chemical safety assessment (Bouhifd et al., 2013; Zhang et al., 2013a,b; Armitage and Barbas, 2014; Sulek et al., 2014). With the application of powerful bioinformatics and statistics, metabolite signatures can be used to identify a PoT which connects the molecular initiating event (MIE) of a toxicant with an adverse outcome (Ankley et al., 2010; Bouhifd et al., 2013; Vinken, 2013; Athersuch, 2016). The development of an underpinning mechanistic toxicology in the form of a perturbed PoT is a key concept for the implementation of the much vaunted Toxicity Testing for the 21st Century (NRC, 2007).

The following are just a few examples illustrating how the identification of in vivo metabolic signatures in pharmaceutical applications, environmental and occupational toxicology and in in vitro systems is a rapidly growing area that could provide actionable data for human chemical safety assessment.

In clinical applications metabolite signatures have been identified in a range of biological fluids that; can distinguish between patients with various cancers including; colorectal, pancreatic, gastric, liver, breast, ovarian, kidney, bladder, prostate, oesophageal, lung and oral and healthy controls (Armitage and Barbas, 2014), are consistent with early indications of diabetes, liver dysfunction and disruption of gut microbiome homeostasis in healthy volunteers (Guo et al., 2015), can distinguish between race and genotype in response to the antihypertensive drug atenolol (Wikoff et al., 2013), and were able to discriminate hepatitis $B$ virus (HBV) infected subjects from healthy controls (Zhang et al., 2013a).

In environmental toxicology, metabolic profiling of urinary metabolites has been shown; to detect early effects of environmental and lifestyle exposure to cadmium in a human population (Ellis et al., 2012), to distinguish controls and alcohol consumers, but not smokers exposed to a complex mixture such as welding fumes (Kuo et al., 2012), to identify intermediate biomarkers of response to environmental/occupational concentrations of lead, cadmium and arsenic, in smelter workers (Dudka et al., 2014), to indicate oxidative stress-related effects in humans exposed to environmental concentrations of polycyclic aromatic hydrocarbons (PAHs) (Wang et al., 2015), and associate male infertility with arsenic exposure caused by a PoT involving oxidative stress and sexual hormone disruption (Shen et al., 2013).

Distinguishable metabolic signatures have been observed in in vitro cultured human fibroblast cells infected by herpes simplex virus type-1 (HSV-1) and human cytomegalovirus (HCMV) (Rabinowitz et al., 2011). In vitro metabolic signatures leading to hepatotoxicity in HepG2/C3a cells in microfluidic culture conditions which appeared consistent with literature reports 
of in vivo hepatotoxicity were identified (Choucha Snouber et al., 2013), and different in vitro hepatic metabolic signatures and pathways for ammonia, dimethylsulfoxide and paracetamol toxicity were identified in liver and kidney co-cultures (Shintu et al., 2012).

\section{DOSE-DEPENDENT METABOLITE SIGNATURES}

To ensure public safety and environmental quality, regulatory agencies are required by law to undertake science-based safety and risk assessments of potential hazards (Burgoon and Zacharewski, 2008). These agencies use dose-response modeling to identify a Reference Point (RP), also known as a point-of-departure $(\mathrm{PoD})$, which is the point of transition on the dose-effect curve, to derive a health-based guidance value (Sand et al., 2006, 2012; Burgoon and Zacharewski, 2008). Therefore, the identification of dose-dependent changes in metabolite signatures would permit the use of such data in the current safety assessment paradigm (European Food Safety Authority, 2014). Encouraging developments in dosedependent changes in metabolic biomarkers in both in vivo and in vitro studies are increasingly reported. For example, dose-dependent changes were observed in urinary metabolite biomarkers of male infertility in Han Chinese men following environmental exposure to arsenic, and in cadmium-induced renal toxicity in Chinese women (Gao et al., 2014). In addition, the metabolomic changes observed in the latter study were sufficiently distinct to allow the differentiation of cadmiuminduced renal toxicity from subjects with chronic kidney disease (Gao et al., 2014). In male Sprague Dawley rats treated with 0.5 or $2 \mathrm{mg} / \mathrm{kg} \mathrm{HgCl}_{2}$ [mercury(II) chloride] maximal and marked kidney tubule necrosis was observed by $48 \mathrm{~h}$ post exposure at the high dose and modest injury at the low dose (Griffin and Bollard, 2004). In vitro, organ-specific, dosedependent, predictive, compound-specific metabolite signatures for ammonia and paracetamol toxicity were observed in microfluidic liver and kidney co-cultures (Shintu et al., 2012).

The use of metabolite signatures in the safety assessment process could be possible if signatures observed in vivo can be reproduced in appropriate in vitro systems in which doseresponse relationships could be more easily observed and measured (European Food Safety Authority, 2014). There are encouraging developments in the area.

\section{MICROFLUIDICS AND BIOCHIPS}

Common laboratory practice is to use two-dimensional (2D) cell culture techniques, that is, to grow cells on a flat substrate such as a petri dish or microtiter plate (van Duinen et al., 2015). In three-dimensional (3D) cell culture techniques cells are permitted to grow or interact with their surroundings in all three dimensions and have been shown to be an improvement on 2D cultures (van Duinen et al., 2015). For example, apicalbasal polarization (Schoenenberger et al., 1994), lumen formation (Debnath et al., 2003), reduced proliferation and increased differentiation (Weaver et al., 1997) and numerous changes in RNA and protein expression (Lin and Bissell, 1993).

Yet existing 2D and 3D cell culture models do not fully recapitulate subtle organ-specific variations in the in vivo microenvironment (Huh et al., 2012). In situ, cells experience organ-specific dynamic variations in spatiotemporal chemical gradients and mechanical forces (e.g., cyclic strain, compression, fluid shear stresses) in their local tissue microenvironment that are crucial governors of their survival, growth and function. Thus, many fundamental aspects of cell behavior are mechanosensitive, including adhesion, spreading, migration, gene expression and cell-cell interactions (Jansen et al., 2015). Integrin-mediated mechanosensing feeds into cell fate decisions by activating various downstream signaling cascades connected to gene expression (Jansen et al., 2015).

Microfluidic techniques are based on micrometer-sized, hollow channels lined with living cells arranged to recreate tissueand organ-level physiology which are continuously perfused with nutrient medium (Huh et al., 2010, 2012, 2013; Tseng et al., 2014; van Duinen et al., 2015). These technologies, also known as biochips and are about the size of a computer memory stick, further increase the physiological relevance of 3D cell culture by enabling spatially controlled co-cultures e.g., liver and kidney, perfusion flow and spatial control over signaling gradients (Smith et al., 2013; Tseng et al., 2014; van Duinen et al., 2015). The detection of a metabolomic signature in a co-cultured biochip should, in theory, be similar to an in vivo blood or urine metabolomic signature as they are all aggregate responses to a chemical stressor.

When coupled to metabolomics and intracellular gene and protein levels, biochips have the potential to provide a functional cell response. They can behave as "biosensor" systems when combined with metabolomic studies of organ culture media that may be useful in a high-throughput small-molecule screening approach (Prot et al., 2012). Indeed, biochips are being developed for high-throughput assay development (Prot and Leclerc, 2012; Prot et al., 2012; Trietsch et al., 2013). In addition, advances in real-time quantification of changes in intracellular metabolic activities have the potential to vastly improve the prediction of current and future cellular phenotypes based on metabolomic signatures (Heinemann et al., 2014). A proof-ofprinciple microfluidic-based inline small molecule extraction system which allows for continuous metabolomics analysis of living systems has been developed. This technology could detect cyclic patterns and forecastable metabolic trajectories. Metabolic oscillations and predictable transitions in both growth and stress related changes in E. coli and ovine whole blood could be observed and measured (Heinemann et al., 2014). The combination of recent advances in stem cell biology, such as induced pluripotent stem cells (Moreno et al., 2015) and organoid technology (Astashkina et al., 2012), with microfluidic 3D cell culture will lead to the implementation of personalized medicine and companion diagnostics in the next 5 years (van Duinen et al., 2015). 
However, specific metabolite signatures have been observed that are a cellular response to the culture mode and cellular environment in biochips (Choucha Snouber et al., 2013; Sturla et al., 2014). For example, a cytoprotective cell response was induced in HepG2/C3a cells by the microfluidic biochip conditions (Prot et al., 2011). Also, there are differences in response between biochips and conventional plate cultures (Prot et al., 2012). The latter may occur due to differences in mechanosensing (Huh et al., 2012; Jansen et al., 2015). These must be distinguished from specific signatures that are consistent with those observed in vivo (Prot et al., 2012). Nonetheless, transcriptomic and proteomic signatures of acetaminophen toxicity observed in cultured HepG2/C3A cells in a microfluidic biochip study have been shown to be similar to those reported in vivo (Prot et al., 2011). Many more examples like that of acetaminophen, encompassing a representative chemical space, are required in order to provide the evidence base to replace animal-based toxicity testing.

\section{VALIDATION OF BIOCHIP DATA}

Validation is the independent assessment of the scientific basis, the reproducibility, and the predictive capacity of a test. Currently, the validation of in vitro models is a significant challenge in drug candidate and toxicity screening. High percentages of new chemicals and biological entities still fail late-stage human drug testing, or receive regulatory "black box" warnings, or are removed from the market for safety reasons after regulatory approval (van Duinen et al., 2015). There are a number of reasons for the perception that in vitro cellbased assays and subsequent preclinical in vivo studies do not yet provide sufficient pharmacological and toxicity data or reliable predictive capacity for understanding drug candidate and environmental chemical performance in vivo (Adler et al., 2011; Astashkina et al., 2012; Piersma et al., 2014). The discussion of the regulatory acceptance of in vitro data for safety assessment is beyond the scope of this review. However, the reader may find the reviews of Adler et al. (2011) and Piersma et al. (2014) useful.

A key problem for the novel technologies is the absence of a point of reference, i.e., a "traditional test" or "gold standard." In the absence of reference data, "scientific validation" needs to be stressed. This would involve a systematic review of the extent to which a given test reflects current scientific understanding. In the case of toxicity, this would require review of established modes of action (MOA), PoT and AOPs. This is in contrast to traditional validation, which largely considers the test system as a black box and compares the results obtained therein with those of another black box, the animal model(s) (Pamies et al., 2014). However, because of their origin human-derived 3D cell culture models are expected to be better predictors of clinical and toxic outcome than animal models (van Duinen et al., 2015). Retrospective validation based on clinical results for success or failure of compounds with regards to toxicology should be used as RPs for validation (van Duinen et al., 2015). Nonetheless, more human toxicity data and high-quality in vivo data are critical in assessing the true predictive power of in vitro databased models of in vivo toxicity (Huang et al., 2016). Although historically these data, in many cases are not publicly available, particularly for drugs, there are increasingly numerous new freely available databases that may provide such data, e.g., the Human Metabolome Database (Wishart et al., 2013) and Consensus Path Database (ConsensusPathDB-human) (Kamburov et al., 2013). Therefore, an alternative validation strategy would be to compare biochemical changes between an in vitro model system and in vivo human interaction networks such as gene, protein, signaling, metabolic and drug-target interactions as well as gene regulation and biochemical pathway perturbations (Dumas, 2012; Kamburov et al., 2013; European Food Safety Authority, 2014).

\section{CHARACTERISATION OF HUMAN EXPOSURE}

The estimation of human exposure is of fundamental importance in the evaluation of the relevance and interpretation of doseresponse data for toxicity in the assessment of health risks (Thomas et al., 2013). Therefore, a PoD determined in an in vitro system must be extrapolated to an in vivo $\mathrm{PoD}$, which in turn must be related to an administered dose or tissue dose arising from human exposure (Thomas et al., 2013; Wetmore et al., 2015).

Human exposure may be estimated from the measurement of parent chemical concentrations in the blood or urinary metabolite concentrations from which exposure concentrations can be inferred using reverse dosimetry (Tan et al., 2006; Lyons et al., 2008; McNally et al., 2012, 2014). This approach could be appropriate in the case of blood parent chemical or urinary metabolite concentrations of known environmental pollutants measured as part of a metabolic profile.

For chemicals without biological monitoring data, as would be the case with a PoD derived from biochips, high-throughput human exposure models are being developed which combine environmental fate and transport models with indoor or consumer exposure models (Arnot et al., 2010, 2012; Wambaugh et al., 2013, 2014, 2015; Wetmore et al., 2015). Comparison of the administered dose or tissue dose with human exposure predictions could provide a margin of exposure (MOE) approach that can help the shift from a hazard based- toward a more risk-based- methodology (Thomas et al., 2013; Wetmore et al., 2015).

\section{BIOINFORMATICS: PATHWAY AND NETWORK ANALYSIS}

Omics data must distinguish changes and pathways associated with impending pathology versus benign adaptive changes that are responsive to the chemical but are not associated with toxicity (Harrill and Rusyn, 2008). More and more powerful data analytics required to distinguish biological signals from noise are increasingly available (Braun, 2014). Once 
identified metabolomic signatures provide relevance beyond clinical biomarkers as they represent a powerful means of identifying mechanisms of toxicity and disease (Wikoff et al., 2013; Zhang et al., 2013a).

The rapid proliferation of metabolomics studies has led to difficulties in the identification of compounds, their physiological role or toxicity or disease-specific pathway (Collins, 2004). The Human Metabolome Database or HMDB is a resource designed to address these issues. It is an open access database with up-to-date referential information about metabolites, metabolic pathways, biomarkers and reference NMR, MS/MS (tandem mass spectrometry), and GC-MS (gas chromatography mass spectrometry) spectra for compound identification (Wishart, 2007; Wishart et al., 2009, 2013, 2016). At the time of writing the HMDB contains 41,993 metabolite entries, more than 5000 normal and abnormal metabolite concentrations and nearly 800 metabolic and disease-associated pathways and dozens of cancer biomarkers (Wishart et al., 2016). However, currently only a fraction of the known human metabolome is linked to pathways and secondary processes such as gut microbiome-generated effects and lipid metabolism (Wikoff et al., 2009, 2013). Even with the growing number of knowledge-based metabolic pathway databases that can be used to reveal the higher-order systemic operation of cells, organs and whole organisms (Stobbe et al., 2014; Zhukova and Sherman, 2014) more comprehensive tools and databases specifically designed for network and pathway analysis using metabolomics data are required (Xia and Wishart, 2010a,b; Kankainen et al., 2011; Wikoff et al., 2013). For example, perturbed metabolic pathways have been identified by mapping transcriptomic, proteomic and metabolomics data signatures using freely available resources such as the KEGG database and Ingenuity canonical pathways (Prot et al., 2012; Posma et al., 2014). However, few network mapping programs consider that the typical mammal has metabolic contributions from symbiotic gut microbiota and even parasitic organisms (Gill et al., 2006; Nicholson et al., 2012). MetaboNetworks, a freely available tool for the identification of complex metabolic reaction networks, combines metabolic reactions from different organisms and allows the delineation and combination of reaction networks from selected and combined organisms (Posma et al., 2014).

Another promising web-based tool is the ConsensusPathDBhuman where human in vivo signatures may be identified by interrogating 32 freely accessible databases accessed via a single portal (Kamburov et al., 2013). The ConsensusPathDB-human integrates interaction networks in humans including binary and complex protein-protein, genetic, metabolic, signaling, gene regulatory and drug-target interactions, as well as biochemical pathways (Kamburov et al., 2013).

However, confidence in the quality and reliability of omics data must be improved. Specifically, significant improvements are necessary in the sensitivity, accuracy and reproducibility of these data (Leung et al., 2013). Biological variation and differences in "time of capture" of samples and inter-laboratory variation can lead to a lack of reproducibility (Leung et al., 2013).

There are efforts under way that combine high quality omics and phenome data in the same database that are already demonstrating an impressive level of sophistication and predictive capability. Currently there is restricted access to the data but they do demonstrate what is possible. For example, the Clinical Genome Resource, which was set up by the US National Human Genome Research Institute, is a database of disease-related variants, and contains information that could guide medical responses to these variants as well as the evidence supporting those associations (Rehm et al., 2015). Genomics England, which runs the 100,000 Genomes Project, aims to bolster progress in this area by establishing 'clinical interpretation partnerships': doctors and researchers will collaborate to establish robust models of diseases that can potentially be mapped to specific genetic alterations (Eisenstein, 2015). This will be achieved by building a database of clinical data with matching rich phenotype data from patient records ${ }^{9}$. Data will remain in a secure environment within which researchers will work (Siva, 2015) ${ }^{10,11}$. The 100,000 Genomes Project provides a monthly update of the number whole human genomes sequenced. As of first February 2016, 6,597 genomes have been sequenced ${ }^{12}$.

The Health Nucleus offered by Human Longevity Inc. ${ }^{13}$ uses whole genome sequence analysis, advanced clinical imaging and innovative machine learning - combined with a comprehensive curation of personal health history - to deliver the most complete picture of individual health. Currently, the database contains 20,000 genomes with matching phenomes with the view of expanding to over one million. The larger the database the more effective the correlations because the 6.5 billion bases in each individual's DNA differs from another individual by just 3\%. The phenome data is generated using the most advanced techniques to measure unique body structures and metabolomics profiles. Machine learning techniques are used to uncover associations. They claim a level of sophistication where genomes can be matched to photographs and voice recordings matched to sex, age, and height and face shape. In the "Face Project" they claim to have matched 100 photographs to 100 genomes $^{14,15}$.

As with all new developments a global initiative involving industry, regulatory agencies and academic institutions is required to standardize 'omics' methods and reach a consensus on the reliability and interpretation of endpoints (Leung et al., 2013).

\section{IN VITRO TO IN VIVO EXTRAPOLATION}

Whilst differentially expressed genes, proteins and metabolites provide a powerful means of understanding mechanisms (specific regulatory or signaling networks altered by treatments) that connect molecular and cellular changes at the tissue level, they are nonetheless "static" lists and therefore cannot provide a complete

\footnotetext{
${ }^{9}$ http://www.genomicsengland.co.uk/the-100000- genomes-project/ (Accessed on 20 May 2016)

${ }^{10} \mathrm{http}: / /$ www.genomicsengland.co.uk/ (Accessed on 20 May 2016)

${ }^{11}$ https://youtu.be/gW6CUCYw7Vs (Accessed on 20 May 2016)

${ }^{12} \mathrm{http}$ //www.genomicsengland.co.uk/the-100000-genomes-project-by-numbers/ (Accessed on 20 May 2016)

${ }^{13} \mathrm{http}: / /$ tinyurl.com/nehe3e4 (Accessed on 20 May 2016)

${ }^{14}$ https://youtu.be/D_JwU UTD-hk (at 7 min $50 \mathrm{~s}$ ) (Accessed on 20 May 2016)

${ }^{15}$ https://youtu.be/4ywjThNbfYk (Accessed on 20 May 2016)
} 
understanding of physiological processes or of toxicity. In order to replace in vivo animal testing and provide a quantitative, dynamic, mechanistic and predictive toxicology, concentrationresponse relationships observed and measured in biochips must be extrapolated to in vivo. This can be done with physiologicallybased pharmacokinetic (PBPK) models (Loizou and Hogg, 2011; McNally et al., 2011, 2012; Prot and Leclerc, 2012; Coecke et al., 2013; Bessems et al., 2014; Sturla et al., 2014).

A PBPK model is an independent, structural model, comprising compartments that correspond directly and realistically to the organs and tissues of the body and connected by the cardiovascular system. They are mathematical descriptions of biological systems, in this case the human body, which are translated into computer code and solved computationally. They are frameworks that can capture our understanding of the science underlying the biological processes that lead to disease (McNally et al., 2011). The principle application of PBPK models is in the prediction of the appropriate form of the target tissue dose, or dose-metric, of the parent chemical or its reactive metabolite(s). The dose-metric must capture the critical biochemical steps that lead to the moiety causing the effect at the target site. Such mechanisms may take place within any compartment, e.g., blood, organ or sub-cellular compartment. Use of an appropriate dose-metric in chemical safety assessment calculations provides a better basis for relating the observed effects to the external or administered exposure concentration of the parent chemical (Conolly and Butterworth, 1995; Barton et al., 1998; IGHRC, 1999; Johanson et al., 1999; Andersen, 2003; Clewell and Clewell, 2008; Lipscomb and Poet, 2008).

Physiologically-based pharmacokinetic models can be used for forward or reverse dosimetry. The former converts inhalation, dermal exposure, oral or intravenous administration of a chemical to a target-tissue dose; the latter can reconstruct exposure or dose from parent chemical and/or metabolite(s) in urine, blood or in vitro surrogates of organ or tissue concentration (Tan et al., 2006; Clewell et al., 2008; Lyons et al., 2008; Louisse et al., 2012; McNally et al., 2012, 2014; Bessems et al., 2014). Therefore, PBPK models can be used to translate a RP derived from concentration-response relationships measured in biochips to a plausible distribution of human in vivo concentrations. This can be achieved by linking a PBPK model with Bayesian inference where replacing single point values for model parameters with informative prior distributions converts a deterministic model to a population-based model (McNally et al., 2012, 2014).

\section{REGULATORY ACCEPTANCE}

In the USA regulatory action must be defensible in court where, in the absence of the preferred proof that something, "is or is not true," the supporting arguments are based on "precedent and expert opinion." Regulators will change their actions when expert scientific opinion supports the use of alternative models over animal models, and regulatory action based on those alternative models can be defended in court i.e., regulators take their cues from expert scientists who provide them with legally defensible actions, not the other way around.

In the absence of a way to measure the "accuracy" of a new test versus existing animal test results, the default is to prove that an alternative-to-animals test produces results that are "similar" or "comparable" to the previous animal studies. If the results are different, then the alternative system cannot replace the animal studies, i.e., current practice and historical precedent win.

The emergence of human data, such as, chemical body burdens (i.e., full chemical and metabolite profiles) and biomarkers of effects for health status or steps along an AOP progression should change the current paradigm. The burden of proof to "validate" a new test should not require comparison with animal data, but should be which test provides the most accurate result to best protect public health. More accurate estimates of risk to protect public health based on human in vivo data must be considered more relevant and less uncertain than an estimate based on current practice which is derived from a few animal test results, primarily in rodents, adjusted by uncertainty factors which are scientifically poorly supported.

In Europe, the regulatory objective in not to obtain the most accurate estimate of risk, rather it is to drive the control of exposure to a level at which there is confidence of no significant risk. Regulatory acceptance is based more on understanding, transparency and robustness of new approaches and adherence with the stipulations of the regulations. European regulatory authorities must be confident in new technologies in order to adopt them and would generally do so without reference to court proceedings.

\section{THE NEAR FORESEEABLE FUTURE}

If "foreseeable" refers to a range of time for which forecasts are possible and "forecasting" is to calculate or predict (some future event or condition) usually as a result of study and analysis of available pertinent data, then the next 5-10 years should see the transformation of occupational and environmental toxicology from a human data poor to a human data rich discipline. This transformation will come about through the coalescence of systems medicine and the digital revolution, the components of which, will in turn coalesce with the highthroughput in vitro systems- based toxicity testing paradigm proposed in the US National Research Council vision and strategy for future toxicity testing and safety assessment (NRC, 2007). The generation of human data that may be used in chemical safety assessment continues. For example, the development of a fully integrated wrist-band sensor for in situ analysis of sweat can provide real-time assessment of the physiological state of human subjects and may represent a platform for the development of a wide range of personalized diagnostic and physiological monitoring applications (Gao et al., 2016). Human sweat is a medium considered to be rich in physiological information (Sonner et al., 2015). It is reasonable to predict that the sophisticated sampling technology developed for such a device could be used to provide sweat samples for frequent, non-invasive 
metabolic profiling. Likewise, the development of relatively lowcost "electronic noses" for the non-invasive analysis of volatile organic compounds (VOCs) signatures in exhaled breath for the early detection of various cancers and other diseases must also bode well for the near future (Konvalina and Haick, 2013; Rattray et al., 2014; Krilaviciute et al., 2015; Gasparri et al., 2016).

Optimism for the development of an animal-free chemical safety assessment paradigm based on the identification of presymptomatic, diagnostic and prognostic metabolic signatures of toxicity and disease using non-invasive or minimally invasive biosensors appears to be justified.

\section{AUTHOR CONTRIBUTIONS}

This review is entirely the work of GL.

\section{REFERENCES}

Adler, S., Basketter, D., Creton, S., Pelkonen, O., van Benthem, J., Zuang, V., et al. (2011). Alternative (non-animal) methods for cosmetics testing: current status and future prospects-2010. Arch. Toxicol. 85, 367-485. doi: 10.1007/s00204011-0693-2

Alyass, A., Turcotte, M., and Meyre, D. (2015). From big data analysis to personalized medicine for all: challenges and opportunities. BMC Med. Genomics 8:33. doi: 10.1186/s12920-015-0108-y

Andersen, M. E. (2003). Toxicokinetic modeling and its applications in chemical risk assessment. Toxicol. Lett. 138, 9-27. doi: 10.1016/S0378-4274(02) 00375-2

Andersen, M. E., Thomas, R. S., Gaido, K. W., and Conolly, R. B. (2005). Dose-response modeling in reproductive toxicology in the systems biology era. Reprod. Toxicol. 19, 327-337. doi: 10.1016/j.reprotox.2004. 12.004

Ankley, G. T., Bennett, R. S., Erickson, R. J., Hoff, D. J., Hornung, M. W., Johnson, R. D., et al. (2010). Adverse outcome pathways: a conceptual framework to support ecotoxicology research and risk assessment. Environ. Toxicol. Chem. 29, 730-741. doi: 10.1002/etc.34

Armitage, E. G., and Barbas, C. (2014). Metabolomics in cancer biomarker discovery: current trends and future perspectives. J. Pharm. Biomed. Anal. 87, 1-11. doi: 10.1016/j.jpba.2013.08.041

Arnot, J. A., Brown, T. N., Wania, F., Breivik, K., and McLachlan, M. S. (2012). Prioritizing chemicals and data requirements for screening-level exposure and risk assessment. Environ. Health Perspect. 120, 1565-1570. doi: 10.1289/ehp.1205355

Arnot, J. A., Mackay, D., Parkerton, T. F., Zaleski, R. T., and Warren, C. S. (2010). Multimedia modeling of human exposure to chemical substances: the roles of food web biomagnification and biotransformation. Environ. Toxicol. Chem. 29, 45-55. doi: 10.1002/etc. 15

Astashkina, A., Mann, B., and Grainger, D. W. (2012). A critical evaluation of in vitro cell culture models for high-throughput drug screening and toxicity. Pharmacol. Ther. 134, 82-106. doi: 10.1016/j.pharmthera.2012. 01.001

Athersuch, T. (2016). Metabolome analyses in exposome studies: profiling methods for a vast chemical space. Arch. Biochem. Biophys. 589, 177-186. 10.1016/j.abb.2015.10.007.

Bains, S. (2009). Open access movement. Concept 1.

Barton, H. A., Andersen, M. E., and Clewell, H. J. III (1998). Harmonisation: developing consistent guidelines for applying mode of action and dosimetry information to cancer and noncancer risk assessment. Hum. Ecol. Risk Assess. 4, 74-115. doi: 10.1080/10807039891284226

Bessems, J. G., Loizou, G., Krishnan, K., Clewell, H. J. III, Bernasconi, C., Bois, F., et al. (2014). PBTK modelling platforms and parameter estimation tools to enable animal-free risk assessment: recommendations from a joint EPAA -

\section{FUNDING}

This publication and the work it describes were funded by the Health and Safety Executive (HSE). Its contents, including any opinions and/or conclusions expressed, are those of the author alone and do not necessarily reflect HSE policy.

\section{ACKNOWLEDGMENTS}

The author thanks Dr. Rob DeWoskin for his helpful comments in general and on regulatory acceptance in the USA in particular and Dr. Steve Fairhurst for the UK and European perspective on regulatory acceptance and Dr. Julia Fentem and Dr. Carl Westmoreland of Unilever, UK for their general comments.

EURL ECVAM ADME workshop. Regul. Toxicol. Pharmacol. 68, 119-139. doi: 10.1016/j.yrtph.2013.11.008

Bouhifd, M., Andersen, M. E., Baghdikian, C., Boekelheide, K., Crofton, K. M., Fornace, A. J., et al. (2015). The human toxome project. Altex 32, 112-124. doi: 10.14573/altex.1502091

Bouhifd, M., Hartung, T., Hogberg, H. T., Kleensang, A., and Zhao, L. (2013). Review: toxicometabolomics. J. Appl. Toxicol. 33, 1365-1383. doi: $10.1002 /$ jat.2874

Bouhifd, M., Hogberg, H. T., Kleensang, A., Maertens, A., Zhao, L., and Hartung, T. (2014). Mapping the human toxome by systems toxicology. Basic Clin. Pharmacol. Toxicol. 115, 24-31. doi: 10.1111/bcpt.12198

Braun, R. (2014). Systems analysis of high-throughput data. Adv. Exp. Med. Biol. 844, 153-187. doi: 10.1007/978-1-4939-2095-2_8

Burden, N., Sewell, F., Andersen, M. E., Boobis, A., Chipman, J. K., Cronin, M. T. D., et al. (2015). Adverse outcome pathways can drive nonanimal approaches for safety assessment. J. Appl. Toxicol. 971-975. doi: 10.1002/jat.3165

Burgoon, L. D., and Zacharewski, T. R. (2008). Automated quantitative dose-response modeling and point of departure determination for large toxicogenomic and high-throughput screening data sets. Toxicol. Sci. 104, 412-418. doi: 10.1093/toxsci/kfn083

Calvani, R., Miccheli, A., Capuani, G., Tomassini Miccheli, A., Puccetti, C., Delfini, M., et al. (2010). Gut microbiome-derived metabolites characterize a peculiar obese urinary metabotype. Int. J. Obes. 34, 1095-1098. doi: 10.1038/ijo.2010.44

Chen, R., and Snyder, M. (2012). Systems biology: personalized medicine for the future? Curr. Opin. Pharmacol. 12, 623-628. doi: 10.1016/j.coph.2012. 07.011

Choucha Snouber, L., Bunescu, A., Naudot, M., Legallais, C., Brochot, C., Dumas, M. E., et al. (2013). Metabolomics-on-a-chip of hepatotoxicity induced by anticancer drug flutamide and Its active metabolite hydroxyflutamide using HepG2/C3a microfluidic biochips. Toxicol. Sci. 132, 8-20. doi: $10.1093 /$ toxsci/kfs 230

Clarke, C. J., and Haselden, J. N. (2008). Metabolic profiling as a tool for understanding mechanisms of toxicity. Toxicol. Pathol. 36, 140-147. doi: $10.1177 / 0192623307310947$

Clayton, T. A., Lindon, J. C., Cloarec, O., Antti, H., Charuel, C., Hanton, G., et al. (2006). Pharmaco-metabonomic phenotyping and personalized drug treatment. Nature 440, 1073-1077. doi: 10.1038/nature04648

Clewell, H. J., Tan, Y. M., Campbell, J. L., and Andersen, M. E. (2008). Quantitative interpretation of human biomonitoring data. Toxicol. Appl. Pharmacol. 231, 122-133. doi: 10.1016/j.taap.2008.04.021

Clewell, R. A., and Clewell, H. J. III (2008). Development and specification of physiologically based pharmacokinetic models for use in risk assessment. Reg. Toxicol. Pharmacol. 50, 129-143. doi: 10.1016/j.yrtph.2007. 10.012 
Coecke, S., Pelkonen, O., Leite, S. B., Bernauer, U., Bessems, J. G., Bois, F. Y., et al. (2013). Toxicokinetics as a key to the integrated toxicity risk assessment based primarily on non-animal approaches. Toxicol. In Vitro 27, 1570-1577. doi: 10.1016/j.tiv.2012.06.012

Coen, M., Holmes, E., Lindon, J. C., and Nicholson, J. K. (2008). NMRbased metabolic profiling and metabonomic approaches to problems in molecular toxicology. Chem. Res. Toxicol. 21, 9-27. doi: 10.1021/tx70 0335d

Collins, F. S. (2004). The case for a US prospective cohort study of genes and environment. Nature 429, 475-477. doi: 10.1038/nature02628

Collins, F. S., and Varmus, H. (2015). A new initiative on precision medicine. N. Engl. J. Med. 372, 793-795. doi: 10.1056/NEJMp1500523

Conolly, R. B., and Butterworth, B. E. (1995). Biologically based dose response model for hepatic toxicity: a mechanistically based replacement for traditional estimates of noncancer risk. Toxicol. Lett. 82-83, 901-906. doi: 10.1016/03784274(95)03528-1

Cote, I., Burgoon, L., and DeWoskin, R. (2014). Next Generation Risk Assessment: Incorporation of Recent Advances in Molecular, Computational, and Systems Biology. Final Report EPA/600/R-14/004. Washington, DC: U.S. Environmental Protection Agency.

De Wever, B., Goldberg, A., Eskes, C., Roggen, E., Vanparys, P., Schröder, K., et al. (2015). "Open source"-based engineered human tissue models: a new gold standard for nonanimal testing through openness, transparency, and collaboration, promoted by the ALEXANDRA Association. Appl. In Vitro Toxicology 1, 5-9. doi: 10.1089/aivt.2014.0011

Dearry, A. (2013). Integrating environmental health data to advance discovery. Paper Presented at the Emerging Science for Environmental Health Decisions, Washington, DC.

Debnath, J., Muthuswamy, S. K., and Brugge, J. S. (2003). Morphogenesis and oncogenesis of MCF-10A mammary epithelial acini grown in threedimensional basement membrane cultures. Methods 30, 256-268. doi: 10.1016/S1046-2023(03)00032-X

Dudka, I., Kossowska, B., Senhadri, H., Latajka, R., Hajek, J., Andrzejak, R., et al. (2014). Metabonomic analysis of serum of workers occupationally exposed to arsenic, cadmium and lead for biomarker research: a preliminary study. Environ. Int. 68, 71-81. doi: 10.1016/j.envint.2014.03.015

Dumas, M. E. (2012). Metabolome 2.0: quantitative genetics and network biology of metabolic phenotypes. Mol. BioSyst. 8, 2494-2502. doi: 10.1039/c2mb25167a

Edwards, S. W., Tan, Y. M., Villeneuve, D. L., Meek, M. E., and McQueen, C. A. (2016). Adverse outcome pathways-organizing toxicological information to improve decision making. J. Pharmacol. Exp. Ther. 356, 170-181. doi: 10.1124/jpet.115.228239

Eisenstein, M. (2015). Big data: the power of petabytes. Nature 527, S2-S4. doi: $10.1038 / 527 \mathrm{~S} 2 \mathrm{a}$

Ellis, J. K., Athersuch, T. J., Thomas, L. D., Teichert, F., Perez-Trujillo, M., Svendsen, C., et al. (2012). Metabolic profiling detects early effects of environmental and lifestyle exposure to cadmium in a human population. $B M C$ Med. 10:61. doi: 10.1186/1741-7015-10-61

European Food Safety Authority (2014). Modern methodologies and tools for human hazard assessment of chemicals. EFSA J. 12, 1-87.

Fan, R., Vermesh, O., Srivastava, A., Yen, B. K., Qin, L., Ahmad, H., et al. (2008). Integrated barcode chips for rapid, multiplexed analysis of proteins in microliter quantities of blood. Nat. Biotechnol. 26, 1373-1378. doi: $10.1038 /$ nbt. 1507

Feinberg, A. P. (2010). Epigenomics reveals a functional genome anatomy and a new approach to common disease. Nat. Biotechnol. 28, 1049-1052. doi: 10.1038/nbt1010-1049

Feinberg, A. P., Irizarry, R. A., Fradin, D., Aryee, M. J., Murakami, P., Aspelund, T., et al. (2010). Personalized epigenomic signatures that are stable over time and covary with body mass index. Sci. Transl. Med. 2:49ra67. doi: 10.1126/scitranslmed.3001262

Fentem, J., Chamberlain, M., and Sangster, B. (2004). The feasibility of replacing animal testing for assessing consumer safety: a suggested future direction. Altern. Lab. Anim. 32, 617-623.

Fiehn, O. (2001). Combining genomics, metabolome analysis, and biochemical modelling to understand metabolic networks. Comp. Funct. Genomics 2, 155168. doi: $10.1002 / \mathrm{cfg} .82$
Galas, D. J., and Hood, L. (2009). Systems biology and emerging technologies will catalyze the transition from reactive medicine to predictive, personalized, preventive and participatory (P4) medicine. $I B C$ 1:26.

Gao, W., Emaminejad, S., Nyein, H. Y. Y., Challa, S., Chen, K., Peck, A., et al. (2016). Fully integrated wearable sensor arrays for multiplexed in situ perspiration analysis. Nature 529, 509-514. doi: 10.1038/nature16521

Gao, Y., Lu, Y., Huang, S., Gao, L., Liang, X., Wu, Y., et al. (2014). Identifying early urinary metabolic changes with long-term environmental exposure to cadmium by mass-spectrometry-based metabolomics. Environ. Sci. Technol. 48, 6409-6418. doi: 10.1021/es500750w

Gasparri, R., Santonico, M., Valentini, C., Sedda, G., Borri, A., Petrella, F., et al. (2016). Volatile signature for the early diagnosis of lung cancer. J. Breath Res. 10:016007.

Gill, S. R., Pop, M., Deboy, R. T., Eckburg, P. B., Turnbaugh, P. J., Samuel, B. S., et al. (2006). Metagenomic analysis of the human distal gut microbiome. Science 312, 1355-1359. doi: 10.1126/science.1124234

Griffin, J. L., and Bollard, M. E. (2004). Metabonomics: its potential as a tool in toxicology for safety assessment and data integration. Curr. Drug Metab. 5, 389-398. doi: 10.2174/1389200043335432

Guarner, F., and Malagelada, J. R. (2003). Gut flora in health and disease. Lancet 361, 512-519. doi: 10.1016/S0140-6736(03)12489-0

Guo, L., Milburn, M. V., Ryals, J. A., Lonergan, S. C., Mitchell, M. W., Wulff, J. E., et al. (2015). Plasma metabolomic profiles enhance precision medicine for volunteers of normal health. Proc. Natl. Acad. Sci. U.S.A. 112, E4901-E4910. doi: $10.1073 /$ pnas. 1508425112

Harrill, A. H., and Rusyn, I. (2008). Systems biology and functional genomics approaches for the identification of cellular responses to drug toxicity. Expert. Opin. Drug Metab. Toxicol. 4, 1379-1389. doi: 10.1517/17425255.4.11.1379

Heinemann, J., Noon, B., Mohigmi, M. J., Mazurie, A., Dickensheets, D. L., and Bothner, B. (2014). Real-time digitization of metabolomics patterns from a living system using mass spectrometry. J. Am. Soc. Mass Spect. 25, 1755-1762. doi: $10.1007 / \mathrm{s} 13361-014-0922-\mathrm{z}$

Holmes, E., Holmes and Nicholson, J. K. (2007). Human metabolic phenotyping and metabolome wide association studies. Ernst Schering Found. Symp. Proc. 227-249.

Holmes, E., Wilson, I. D., and Nicholson, J. K. (2008). Metabolic phenotyping in health and disease. Cell 134, 714-717. doi: 10.1016/j.cell.2008.08.026

Hood, L., Balling, R., and Auffray, C. (2012). Revolutionizing medicine in the 21st century through systems approaches. Biotechnol. J. 7, 992-1001. doi: 10.1002/biot.201100306

Hood, L., Flores, M. A., Brogaard, K. R., and Price, N. D. (2013). "Systems medicine and the emergence of proactive $\mathrm{p} 4$ medicine: predictive, preventive, personalized and participatory a2 - Dekker," in Handbook of Systems Biology, eds A. J. Marian Walhout, M. Vidal, and J. Dekker (San Diego, CA: Academic Press), 445-467.

Hood, L., and Friend, S. H. (2011). Predictive, personalized, preventive, participatory (P4) cancer medicine. Nat. Rev. Clin. Oncol. 8, 184-187. doi: 10.1038/nrclinonc.2010.227

Hood, L., Lovejoy, J. C., and Price, N. D. (2015). Integrating big data and actionable health coaching to optimize wellness. BMC Med. 13:4. doi: 10.1186/s12916-0140238-7

Huang, R., Xia, M., Sakamuru, S., Zhao, J., Shahane, S. A., Attene-Ramos, M., et al. (2016). Modelling the Tox 2110 [thinsp]K chemical profiles for in vivo toxicity prediction and mechanism characterization. Nat. Commun. 7:10425. doi: $10.1038 /$ ncomms 10425

Huh, D., Kim, H. J., Fraser, J. P., Shea, D. E., Khan, M., Bahinski, A., et al. (2013). Microfabrication of human organs-on-chips. Nat. Protoc. 8, 2135-2157. doi: 10.1038/nprot.2013.137

Huh, D., Matthews, B. D., Mammoto, A., Montoya-Zavala, M., Hsin, H. Y., and Ingber, D. E. (2010). Reconstituting organ-level lung functions on a chip. Science 328, 1662-1668. doi: 10.1126/science. 1188302

Huh, D., Torisawa, Y. S., Hamilton, G. A., Kim, H. J., and Ingber, D. E. (2012). Microengineered physiological biomimicry: organs-on-chips. Lab. Chip 12, 2156-2164. doi: 10.1039/c2lc40089h

IGHRC (1999). Physiologically-based Pharmacokinetic Modelling: A Potential Tool for Use in risk Assessment. Available at: http://www.iehconsulting.co.uk/IEH_ Consulting/IEHCPubs/IGHRC/cr4.pdf 
Jack, J., Wambaugh, J., and Shah, I. (2013). Systems toxicology from genes to organs. Methods Mol. Biol. 930, 375-397. doi: 10.1007/978-1-62703-059-5_17

Jansen, K. A., Donato, D. M., Balcioglu, H. E., Schmidt, T., Danen, E. H., and Koenderink, G. H. (2015). A guide to mechanobiology: where biology and physics meet. Biochim. Biophys. Acta 1853(Pt B), 3043-3052. doi: 10.1016/j.bbamcr.2015.05.007

Johanson, G., Jonsson, F., and Bois, F. (1999). Development of new technique for risk assessment using physiologically based toxicokinetic models. Am. J. Ind. Med., 101-103.

Jones, D. P., Park, Y., and Ziegler, T. R. (2012). Nutritional metabolomics: progress in addressing complexity in diet and health. Annu. Rev. Nutr. 32, 183-202. doi: 10.1146/annurev-nutr-072610-145159

Kamburov, A., Stelzl, U., Lehrach, H., and Herwig, R. (2013). The ConsensusPathDB interaction database: 2013 update. Nucleic Acids Res. 41, D793-D800. doi: 10.1093/nar/gks1055

Kankainen, M., Gopalacharyulu, P., Holm, L., and Oresic, M. (2011). MPEAmetabolite pathway enrichment analysis. Bioinformatics 27, 1878-1879. doi: 10.1093/bioinformatics/btr278

Keun, H. C., Ebbels, T. M., Antti, H., Bollard, M. E., Beckonert, O., Schlotterbeck, G., et al. (2002). Analytical reproducibility in (1)H NMRbased metabonomic urinalysis. Chem. Res. Toxicol. 15, 1380-1386. doi: $10.1021 / \mathrm{tx} 0255774$

Kim, S., Kim, W., Wei, C. H., Lu, Z., and Wilbur, W. J. (2012). Prioritizing PubMed articles for the comparative toxicogenomic database utilizing semantic information. Database (Oxford) 2012:bas042. doi: 10.1093/database/bas042

Kinross, J., von Roon, A. C., Penney, N., Holmes, E., Silk, D., Nicholson, J. K., et al. (2009). The gut microbiota as a target for improved surgical outcome and improved patient care. Curr. Pharm. Des. 15, 1537-1545. doi: $10.2174 / 138161209788168119$

Kinross, J. M., von Roon, A. C., Holmes, E., Darzi, A., and Nicholson, J. K. (2008). The human gut microbiome: implications for future health care. Curr. Gastroenterol. Rep. 10, 396-403. doi: 10.1007/s11894-008-0075-y

Konvalina, G., and Haick, H. (2013). Sensors for Breath Testing: From Nanomaterials to Comprehensive Disease Detection. Acc Chem Res.

Kosmides, A. K., Kamisoglu, K., Calvano, S. E., Corbett, S. A., and Androulakis, I. P. (2013). Metabolomic fingerprinting: challenges and opportunities. Crit. Rev. Biomed. Eng. 41, 205-221. doi: 10.1615/CritRevBiomedEng.2013007736

Kotera, M., Hirakawa, M., Tokimatsu, T., Goto, S., and Kanehisa, M. (2012). The KEGG databases and tools facilitating omics analysis: latest developments involving human diseases and pharmaceuticals. Methods Mol. Biol. 802, 19-39. doi: $10.1007 / 978-1-61779-400-1 \_2$

Kraly, J. R., Holcomb, R. E., Guan, Q., and Henry, C. S. (2009). Review: microfluidic applications in metabolomics and metabolic profiling. Anal. Chim. Acta 653, 23-35. doi: 10.1016/j.aca.2009.08.037

Krilaviciute, A., Heiss, J. A., Leja, M., Kupcinskas, J., Haick, H., and Brenner, H. (2015). Detection of cancer through exhaled breath: a systematic review. Oncotarget 6, 38643-38657. doi: 10.18632/oncotarget.5938

Kuo, C. H., Wang, K. C., Tian, T. F., Tsai, M. H., Chiung, Y. M., Hsiech, C. M., et al. (2012). Metabolomic characterization of laborers exposed to welding fumes. Chem. Res. Toxicol. 25, 676-686. doi: 10.1021/tx200465e

Leung, E. L., Cao, Z. W., Jiang, Z. H., Zhou, H., and Liu, L. (2013). Network-based drug discovery by integrating systems biology and computational technologies. Brief. Bioinform. 14, 491-505. doi: 10.1093/bib/bbs043

Li, M., Wang, B., Zhang, M., Rantalainen, M., Wang, S., Zhou, H., et al. (2008). Symbiotic gut microbes modulate human metabolic phenotypes. Proc. Natl. Acad. Sci. U.S.A. 105, 2117-2122. doi: 10.1073/pnas.0712038105

Lin, C. Q., and Bissell, M. J. (1993). Multi-faceted regulation of cell differentiation by extracellular matrix. FASEB J. 7, 737-743.

Lipscomb, J. C., and Poet, T. S. (2008). In vitro measurements of metabolism for application in pharmacokinetic modeling. Pharmacol. Ther. 118, 82-103.

Loizou, G. D., and Hogg, A. (2011). MEGen: A Physiologically Based Pharmacokinetic Model Generator. Frontiers in Pharmacology: Predictive Toxicity 2 56, 1-14, 10.3389/fphar.2011.00056.

Loscalzo, J., and Barabasi, A. L. (2011). Systems biology and the future of medicine. Wiley Interdiscip Rev. Syst. Biol. Med. 3, 619-627. doi: 10.1002/wsbm.144

Loscalzo, J., Kohane, I., and Barabasi, A. L. (2007). Human disease classification in the postgenomic era: a complex systems approach to human pathobiology. Mol. Syst. Biol. 3:124. doi: 10.1038/msb4100163
Louisse, J., Verwei, M., Woutersen, R. A., Blaauboer, B. J., and Rietjens, I. M. (2012). Toward in vitro biomarkers for developmental toxicity and their extrapolation to the in vivo situation. Expert. Opin. Drug Metab. Toxicol. 8, 11-27. doi: $10.1517 / 17425255.2012 .639762$

Lyons, M. A., Yang, R. S., Mayeno, A. N., and Reisfeld, B. (2008). Computational toxicology of chloroform: reverse dosimetry using bayesian inference, markov chain monte carlo simulation, and human biomonitoring data. Environ. Health Perspect. 116, 1040-1046. doi: 10.1289/ehp.11079

MacFie, J., O'Boyle, C., Mitchell, C. J., Buckley, P. M., Johnstone, D., and Sudworth, P. (1999). Gut origin of sepsis: a prospective study investigating associations between bacterial translocation, gastric microflora, and septic morbidity. Gut 45, 223-228. doi: 10.1136/gut.45.2.223

Maher, A. D., Zirah, S. F., Holmes, E., and Nicholson, J. K. (2007). Experimental and analytical variation in human urine in $1 \mathrm{H}$ NMR spectroscopybased metabolic phenotyping studies. Anal. Chem. 79, 5204-5211. doi: 10.1021/ac070212f

Mak, H. C. (2015). Trends in precision medicine: an interview with UCSF's Atul Butte. Cell Syst. 1, 254-255. doi: 10.1016/j.cels.2015.10.007

Mastrangelo, A., Armitage, E. G., Garcia, A., and Barbas, C. (2014). Metabolomics as a tool for drug discovery and personalised medicine. A review. Curr. Top. Med. Chem. 14, 2627-2636. doi: 10.2174/1568026614666141215124956

McNally, K., Cotton, R., Cocker, J., Jones, K., Bartels, M., Rick, D., et al. (2012). Reconstruction of exposure to $m$-Xylene from human biomonitoring data using PBPK modelling, Bayesian inference, and Markov Chain Monte Carlo simulation. J. Toxicol. 2012:760281. doi: 10.1155/2012/760281

McNally, K., Cotton, R., Hogg, A., and Loizou, G. (2014). PopGen: a virtual human population generator. Toxicology 315, 70-85. doi: 10.1016/j.tox.2013.07.009

McNally, K., Cotton, R., and Loizou, G. (2011). A workflow for global sensitivity analysis of PBPK models. Front. Pharmacol. 2:31. doi: 10.3389/fphar.2011.00031

Monte, A. A., Brocker, C., Nebert, D. W., Gonzalez, F. J., Thompson, D. C., and Vasiliou, V. (2014). Improved drug therapy: triangulating phenomics with genomics and metabolomics. Hum. Genomics 8:16. doi: 10.1186/s40246-0140016-9

Moreno, E. L., Hachi, S., Hemmer, K., Trietsch, S. J., Baumuratov, A. S., Hankemeier, T., et al. (2015). Differentiation of neuroepithelial stem cells into functional dopaminergic neurons in 3D microfluidic cell culture. Lab. Chip 15, 2419-2428. doi: 10.1039/c5lc00180c

Nicholson, J. K. (2006). Global systems biology, personalized medicine and molecular epidemiology. Mol. Syst. Biol. 2:52. doi: 10.1038/msb4100095

Nicholson, J. K., and Holmes, E. (2006). Global systems biology and personalized healthcare solutions. Discov. Med. 6, 63-70.

Nicholson, J. K., Holmes, E., and Elliott, P. (2008). The metabolome-wide association study: a new look at human disease risk factors. J. Proteome Res. 7, 3637-3638. doi: 10.1021/pr8005099

Nicholson, J. K., Holmes, E., Kinross, J., Burcelin, R., Gibson, G., Jia, W., et al. (2012). Host-gut microbiota metabolic interactions. Science 336, 1262-1267. doi: $10.1126 /$ science. 1223813

Nicholson, J. K., Holmes, E., Lindon, J. C., and Wilson, I. D. (2004). The challenges of modeling mammalian biocomplexity. Nat. Biotechnol. 22, 1268-1274. doi: $10.1038 / \mathrm{nbt} 1015$

Nicholson, J. K., Holmes, E., and Wilson, I. D. (2005). Gut microorganisms, mammalian metabolism and personalized health care. Nat. Rev. Microbiol. 3, 431-438. doi: $10.1038 /$ nrmicro1152

Nicholson, J. K., and Lindon, J. C. (2008). Systems biology: metabonomics. Nature 455, 1054-1056. doi: $10.1038 / 4551054$ a

NRC (2007). Toxicity Testing in the Twenty-First Century: A Vision and a Strategy. Washington, DC: National Research Council, 146.

Pamies, D., Hartung, T., and Hogberg, H. T. (2014). Biological and medical applications of a brain-on-a-chip. Exp. Biol. Med. 239, 1096-1107. doi: $10.1177 / 1535370214537738$

Piersma, A. H., Ezendam, J., Luijten, M., Muller, J. J., Rorije, E., van der Ven, L. T., et al. (2014). A critical appraisal of the process of regulatory implementation of novel in vivo and in vitro methods for chemical hazard and risk assessment. Crit. Rev. Toxicol. 44, 876-894. doi: 10.3109/10408444.2014.940445

Posma, J. M., Robinette, S. L., Holmes, E., and Nicholson, J. K. (2014). MetaboNetworks, an interactive Matlab-based toolbox for creating, customizing and exploring sub-networks from KEGG. Bioinformatics 30, 893-895. doi: 10.1093/bioinformatics/btt612 
Prot, J. M., Aninat, C., Griscom, L., Razan, F., Brochot, C., Guillouzo, C. G., et al. (2011). Improvement of HepG2/C3a cell functions in a microfluidic biochip. Biotechnol. Bioeng. 108, 1704-1715. doi: 10.1002/bit.23104

Prot, J. M., Bunescu, A., Elena-Herrmann, B., Aninat, C., Snouber, L. C., Griscom, L., et al. (2012). Predictive toxicology using systemic biology and liver microfluidic "on chip" approaches: application to acetaminophen injury. Toxicol. Appl. Pharmacol. 259, 270-280. doi: 10.1016/j.taap.2011. 12.017

Prot, J. M., and Leclerc, E. (2012). The current status of alternatives to animal testing and predictive toxicology methods using liver microfluidic biochips. Ann. Biomed. Eng. 40, 1228-1243. doi: 10.1007/s10439-011-0480-5

Raamsdonk, L. M., Teusink, B., Broadhurst, D., Zhang, N., Hayes, A., Walsh, M. C., et al. (2001). A functional genomics strategy that uses metabolome data to reveal the phenotype of silent mutations. Nat. Biotechnol. 19, 45-50.

Rabinowitz, J. D., Purdy, J. G., Vastag, L., Shenk, T., and Koyuncu, E. (2011). Metabolomics in drug target discovery. Cold. Spring Harb. Symp. Quant. Biol. 76, 235-246. doi: 10.1101/sqb.2011.76.010694

Rattray, N. J., Hamrang, Z., Trivedi, D. K., Goodacre, R., and Fowler, S. J. (2014). Taking your breath away: metabolomics breathes life in to personalized medicine. Trends Biotechnol. 32, 538-548. doi: 10.1016/j.tibtech.2014.08.003

Rehm, H. L., Berg, J. S., Brooks, L. D., Bustamante, C. D., Evans, J. P., Landrum, M. J., et al. (2015). ClinGen-the clinical genome resource. N. Engl. J. Med. 372, 2235-2242. doi: 10.1056/NEJMsr1406261

Sakurai, N., Ara, T., Ogata, Y., Sano, R., Ohno, T., Sugiyama, K., et al. (2011). KaPPA-View4: a metabolic pathway database for representation and analysis of correlation networks of gene co-expression and metabolite co-accumulation and omics data. Nucleic Acids Res. 39, D677-D684. doi: 10.1093/nar/gkq989

Sand, S., Ringblom, J., Hakansson, H., and Oberg, M. (2012). The point of transition on the dose-effect curve as a reference point in the evaluation of in vitro toxicity data. J. Appl. Toxicol. 32, 843-849. doi: 10.1002/jat.2757

Sand, S., von Rosen, D., Victorin, K., and Filipsson, A. F. (2006). Identification of a critical dose level for risk assessment: developments in benchmark dose analysis of continuous endpoints. Toxicol. Sci. 90, 241-251. doi: 10.1093/toxsci/kfj057

Schoenenberger, C. A., Zuk, A., Zinkl, G. M., Kendall, D., and Matlin, K. S. (1994). Integrin expression and localization in normal MDCK cells and transformed MDCK cells lacking apical polarity. J. Cell Sci. 107(Pt 2), 527-541.

Schumacher, A., Rujan, T., and Hoefkens, J. (2014). A collaborative approach to develop a multi-omics data analytics platform for translational research. Appl. Transl. Genom. 3, 105-108. doi: 10.1016/j.atg.2014.09.010

Serkova, N. J., Standiford, T. J., and Stringer, K. A. (2011). The emerging field of quantitative blood metabolomics for biomarker discovery in critical illnesses. Am. J. Respir. Crit. Care Med. 184, 647-655. doi: 10.1164/rccm.201103-0474CI

Shen, H., Xu, W., Zhang, J., Chen, M., Martin, F. L., Xia, Y., et al. (2013). Urinary metabolic biomarkers link oxidative stress indicators associated with general arsenic exposure to male infertility in a han chinese population. Environ. Sci. Technol. 47, 8843-8851. doi: 10.1021/es402025n

Shimizu, K., Ogura, H., Goto, M., Asahara, T., Nomoto, K., Morotomi, M., et al. (2006). Altered gut flora and environment in patients with severe SIRS. J. Trauma 60, 126-133. doi: 10.1097/01.ta.0000197374.99755.fe

Shintu, L., Baudoin, R., Navratil, V., Prot, J. M., Pontoizeau, C., Defernez, M., et al. (2012). Metabolomics-on-a-chip and predictive systems toxicology in microfluidic bioartificial organs. Anal. Chem. 84, 1840-1848. doi: $10.1021 / \mathrm{ac} 2011075$

Siva, N. (2015). UK gears up to decode 100,000 genomes from NHS patients. Lancet $385,103-104$.

Smarr, L. (2012). Quantifying your body: a how-to guide from a systems biology perspective. Biotechnol. J. 7, 980-991. doi: 10.1002/biot.201100495

Smith, A. S., Long, C. J., Berry, B. J., McAleer, C., Stancescu, M., Molnar, P., et al. (2013). Microphysiological systems and low-cost microfluidic platform with analytics. Stem Cell Res. Ther. 4(Suppl. 1), S9. doi: 10.1186/ scrt370

Sobradillo, P., Pozo, F., and Agusti, A. (2011). P4 medicine: the future around the corner. Arch. Bronconeumol. 47, 35-40. doi: 10.1016/j.arbres.2010.09.009

Sonner, Z., Wilder, E., Heikenfeld, J., Kasting, G., Beyette, F., Swaile, D., et al. (2015). The microfluidics of the eccrine sweat gland, including biomarker partitioning, transport, and biosensing implications. Biomicrofluidics 9:031301. doi: $10.1063 / 1.4921039$
Stanberry, L., Mias, G. I., Haynes, W., Higdon, R., Snyder, M., and Kolker, E. (2013). Integrative analysis of longitudinal metabolomics data from a personal multi-omics profile. Metabolites 3, 741-760. doi: 10.3390/metabo30 30741

Stobbe, M. D., Jansen, G. A., Moerland, P. D., and van Kampen, A. H. C. (2014). Knowledge representation in metabolic pathway databases. Brief. Bioinform. 15, 455-470. doi: 10.1093/bib/bbs060

Sturla, S. J., Boobis, A. R., FitzGerald, R. E., Hoeng, J., Kavlock, R. J., Schirmer, K., et al. (2014). Systems toxicology: from basic research to risk assessment. Chem. Res. Toxicol. 27, 314-329. doi: 10.1021/tx400410s

Sulek, K., Han, T. L., Villas-Boas, S. G., Wishart, D. S., Soh, S. E., Kwek, K., et al. (2014). Hair metabolomics: identification of fetal compromise provides proof of concept for biomarker discovery. Theranostics 4, 953-959. doi: 10.7150/thno. 9265

Tan, Y. M., Liao, K. H., and Clewell, H. J. III. (2006). Reverse dosimetry: interpreting trihalomethanes biomonitoring data using physiologically based pharmacokinetic modeling. J. Exp. Sci. Environ. Epidemiol. 17, 591-603. doi: $10.1038 /$ sj.jes. 7500540

Thomas, R. S., Philbert, M. A., Auerbach, S. S., Wetmore, B. A., Devito, M. J., Cote, I., et al. (2013). Incorporating new technologies into toxicity testing and risk assessment: moving from 21 st century vision to a data-driven framework. Toxicol. Sci. 136, 4-18. doi: 10.1093/toxsci/kft178

Topol, E. J. (2010). Transforming medicine via digital innovation. Sci. Transl. Med. 2:16cm4. doi: 10.1126/scitranslmed.3000484

Topol, E. J. (2012). The Creative Destruction of Medicine: How the Digital Revolution Will Create Better Health Care. New York, NY: Basic Books.

Topol, E. J. (2014). Individualized medicine from prewomb to tomb. Cell 157, 241-253. doi: 10.1016/j.cell.2014.02.012

Topol, E. J., Steinhubl, S. R., and Torkamani, A. (2015). Digital medical tools and sensors. JAMA 313, 353-354. doi: 10.1001/jama.2014.17125

Trietsch, S. J., Israels, G. D., Joore, J., Hankemeier, T., and Vulto, P. (2013). Microfluidic titer plate for stratified 3D cell culture. Lab. Chip 13, 3548-3554. doi: $10.1039 / \mathrm{c} 31 \mathrm{lc50210d}$

Tseng, P., Weaver, W. M., Masaeli, M., Owsley, K., and Di Carlo, D. (2014). Research highlights: microfluidics meets big data. Lab. Chip 14, 828-832. doi: $10.1039 /$ c4lc90001d

Turnbaugh, P. J., Ley, R. E., Mahowald, M. A., Magrini, V., Mardis, E. R., and Gordon, J. I. (2006). An obesity-associated gut microbiome with increased capacity for energy harvest. Nature 444, 1027-1031. doi: 10.1038/nature 05414

van Duinen, V., Trietsch, S. J., Joore, J., Vulto, P., and Hankemeier, T. (2015). Microfluidic 3D cell culture: from tools to tissue models. Curr. Opin. Biotechnol. 35, 118-126. doi: 10.1016/j.copbio.2015.05.002

Veenstra, T. D. (2012). Metabolomics: the final frontier? Genome Med 4:40. doi: $10.1186 /$ gm 339

Vinken, M. (2013). The adverse outcome pathway concept: a pragmatic tool in toxicology. Toxicology 312, 158-165. doi: 10.1016/j.tox.2013.08.011

Wachter, A., and Beissbarth, T. (2015). pwOmics: an R package for pathwaybased integration of time-series omics data using public database knowledge. Bioinformatics 31, 3072-3074. doi: 10.1093/bioinformatics/btv323

Wambaugh, J. F., Setzer, R. W., Reif, D. M., Gangwal, S., Mitchell-Blackwood, J., Arnot, J. A., et al. (2013). High-throughput models for exposure-based chemical prioritization in the ExpoCast project. Environ. Sci. Technol. 47, 8479-8488. doi: $10.1021 /$ es $400482 \mathrm{~g}$

Wambaugh, J. F., Wang, A., Dionisio, K. L., Frame, A., Egeghy, P., Judson, R., et al. (2014). High Throughput Heuristics for Prioritizing Human Exposure to Environmental Chemicals. Environ. Sci. Technol. 48, 12760-12767. doi: $10.1021 /$ es503583j

Wambaugh, J. F., Wetmore, B. A., Pearce, R., Strope, C., Goldsmith, R., Sluka, J. P., et al. (2015). Toxicokinetic triage for environmental chemicals. Toxicol. Sci. 147, 55-67. doi: 10.1093/toxsci/kfv118

Wang, Z., Zheng, Y., Zhao, B., Zhang, Y., Liu, Z., Xu, J., et al. (2015). Human metabolic responses to chronic environmental polycyclic aromatic hydrocarbon exposure by a metabolomic approach. J. Proteome Res. 14, 25832593. doi: 10.1021/acs.jproteome.5b00134

Weaver, V. M., Petersen, O. W., Wang, F., Larabell, C. A., Briand, P., Damsky, C., et al. (1997). Reversion of the malignant phenotype of human breast cells in 
three-dimensional culture and in vivo by integrin blocking antibodies. J. Cell Biol. 137, 231-245. doi: 10.1083/jcb.137.1.231

Wetmore, B. A., Wambaugh, J. F., Allen, B., Ferguson, S. S., Sochaski, M. A., Setzer, R. W., et al. (2015). Incorporating high-throughput exposure predictions with dosimetry-adjusted in vitro bioactivity to inform chemical toxicity testing. Toxicol. Sci. 148, 121-136. doi: 10.1093/toxsci/kfv171

Wikoff, W. R., Anfora, A. T., Liu, J., Schultz, P. G., Lesley, S. A., Peters, E. C., et al. (2009). Metabolomics analysis reveals large effects of gut microflora on mammalian blood metabolites. Proc. Natl. Acad. Sci. U.S.A. 106, 3698-3703. doi: 10.1073/pnas.0812874106

Wikoff, W. R., Frye, R. F., Zhu, H., Gong, Y., Boyle, S., Churchill, E., et al. (2013). Pharmacometabolomics reveals racial differences in response to atenolol treatment. PLoS ONE 8:e57639. doi: 10.1371/journal.pone.0057639

Williams, A. J., Harland, L., Groth, P., Pettifer, S., Chichester, C., Willighagen, E. L., et al. (2012). Open PHACTS: semantic interoperability for drug discovery. Drug Discov. Today 17, 1188-1198. doi: 10.1016/j.drudis.2012.05.016

Wishart, D. S. (2007). Current progress in computational metabolomics. Brief. Bioinform. 8, 279-293. doi: 10.1093/bib/bbm030

Wishart, D. S. (2012). Chapter 3: Small molecules and disease. PLoS Comput. Biol. 8:e1002805. doi: 10.1371/journal.pcbi.1002805

Wishart, D. S., Jewison, T., Guo, A. C., Wilson, M., Knox, C., Liu, Y., et al. (2013). HMDB 3.0-The Human Metabolome Database in 2013. Nucleic Acids Res. 41, D801-D807. doi: 10.1093/nar/ gks1065

Wishart, D. S., Knox, C., Guo, A. C., Eisner, R., Young, N., Gautam, B., et al. (2009). HMDB: a knowledgebase for the human metabolome. Nucleic Acids Res. 37, D603-D610. doi: 10.1093/nar/gkn810

Wishart, D. S., Mandal, R., Stanislaus, A., and Ramirez-Gaona, M. (2016). Cancer metabolomics and the human metabolome database. Metabolites 6. doi: 10.3390/metabo6010010

Witze, A. (2014). Joint effort nabs next wave of US supercomputers. Nature 515, 324-324. doi: 10.1038/nature.2014.16347
Xia, J., and Wishart, D. S. (2010a). MetPA: a web-based metabolomics tool for pathway analysis and visualization. Bioinformatics 26, 2342-2344. doi: 10.1093/bioinformatics/btq418

Xia, J., and Wishart, D. S. (2010b). MSEA: a web-based tool to identify biologically meaningful patterns in quantitative metabolomic data. Nucleic Acids Res. 38, W71-W77. doi: 10.1093/nar/gkq329

Zhang, A., Sun, H., Han, Y., Yan, G., and Wang, X. (2013a). Urinary metabolic biomarker and pathway study of hepatitis B virus infected patients based on UPLC-MS system. PLOS ONE 8:e64381. doi: 10.1371/journal.pone. 0064381

Zhang, A., Sun, H., Xu, H., Qiu, S., and Wang, X. (2013b). Cell metabolomics. Omics 17, 495-501. doi: 10.1089/omi.2012.0090

Zhang, Q., Bhattacharya, S., Andersen, M. E., and Conolly, R. B. (2010). Computational systems biology and dose-response modeling in relation to new directions in toxicity testing. J. Toxicol. Environ. Health B. Crit. Rev. 13, 253-276. doi: 10.1080/10937404.2010.483943

Zhu, Y., Davis, S., Stephens, R., Meltzer, P. S., and Chen, Y. (2008). GEOmetadb: powerful alternative search engine for the Gene Expression Omnibus. Bioinformatics 24, 2798-2800. doi: 10.1093/bioinformatics/btn520

Zhukova, A., and Sherman, D. J. (2014). Knowledge-based generalization of metabolic models. J. Comput. Biol. 21, 534-547. doi: 10.1089/cmb.2013.0143

Conflict of Interest Statement: The author declares that the research was conducted in the absence of any commercial or financial relationships that could be construed as a potential conflict of interest.

Copyright $\odot 2016$ Loizou. This is an open-access article distributed under the terms of the Creative Commons Attribution License (CC BY). The use, distribution or reproduction in other forums is permitted, provided the original author(s) or licensor are credited and that the original publication in this journal is cited, in accordance with accepted academic practice. No use, distribution or reproduction is permitted which does not comply with these terms. 